\title{
Economic and operational risks in wind energy projects in Latvia
}

\author{
D. Bezrukovs and A. Sauhatas ${ }^{1}$ \\ ${ }^{1}$ Department of Electric Power Systems \\ Riga Technical University \\ Kalku iela 1, Centra rajons, 1658 Riga (Latvia) \\ Phone/Fax number:+37129187467, e-mail: dbezrukovs@gmail.com, sauhatas@eef.rtu.Iv
}

\begin{abstract}
The paper addresses the problem of economic and operational uncertainty in wind energy projects associated with the volatility of wind speed, concurrent electricity market prices and technical characteristics of wind turbines. The study proposes a comprehensive approach towards the feasibility evaluation of wind energy projects in the conditions of limited wind speed data availability at high altitudes and deregulated electricity market in Latvia. The study performs a sensitivity analysis of wind generator efficiency and revenue generation potential across the range of technical and economic factors. The study uses Stochastic Differential Equation (SDE) models for the out-of-sample forecasting of wind speed and electricity prices in combination with Monte Carlo simulation technique in order to come-up with the distribution of revenue projections and efficiency estimates for a hypothetical wind park. A broad range of project development scenarios involving several wind generator types and multiple mast height options is considered. The study is based on proprietary high frequency wind measurements data gathered in the north-western coastal part of Latvia at the range of altitudes of up to $50 \mathrm{~m}$ and daily electricity market prices from the Latvian segment of Nord Pool power market. The results of the study provide quantitative basis for optimal decision-making process at the planning stage of wind energy projects and highlight the importance of the initial choice of wind generator models.
\end{abstract}

\section{Key words}

Wind speed forecasts, sensitivity analysis, wind measurements, wind turbines, SDE models.

\section{Introduction}

The role of renewable energy source (RES) in Latvia has historically been exceptionally high due the contribution of hydro power stations to the overall electricity production. In 2015 hydro power stations accounted for one third of the installed electrical capacity and for $30 \%$ of the electricity production in the country. Overall installed capacity of RES power stations in Latvia reached $1.8 \mathrm{GW}$ in 2015 that favourably compares to other Baltic countries; however, the level of installed capacities of wind power plants is small even compared to the two neighbouring countries, where capacities are at least fourfold higher than in Latvia (see Table III in the Annex). Because of the large existing installed capacities of RES the economy was lacking stimulus for the development of wind energy power plants.
Although the overall level of installed wind power plant capacity in Latvia is unsatisfactory low, this type of RES has been persistently gaining importance in the overall mix of energy generation sources. The amount of installed capacities of wind power plants grew from negligible 2 MW in year 2001 to almost 70 MW by the end of 2015 . Over the last ten years, in the period from 2004 to 2015, the installed capacity of wind power parks has been growing with the Compound Annual Growth Rate (CAGR) of $10.3 \%$ that compares to only $1.3 \%$ growth rate in the installed capacity of RES power plants of all types in the country over the same period (see Fig. 14). The amount of produced electrical energy by wind power plants in Latvia has been growing with CAGR of $11.1 \%$ over the last ten years, that led to the increase of wind power energy share in the overall electricity production to $2.3 \%$ in 2015.

Apart from the overwhelming dominance of cost-efficient hydropower in the mix of RES in Latvia, the reason for the unsatisfactory low level of installed wind energy capacities can be found in the high level of operational and economic uncertainty associated with the projects. From the perspective of the government, sub-optimal level of investments in renewable energy projects requires subsidies that address the problem of high economic uncertainty. Consequently, in order to promote energy production from RES, Latvian government introduced subsidies in the form of long-term contracts and higher feed-in tariffs. According to the Latvian legislation, wind power electricity producers can sell electricity to the grid under the "compulsory purchase" scheme for the price of around 120 EUR/MWh during the first 10 years of operations and for $72 \mathrm{EUR} / \mathrm{MWh}$ during the subsequent 10 years. Subsidized electricity tariffs for renewable energy made the operations of wind generator farms profitable, making this field more attractive for international investors. Such approach is in line with the EU Directive 2009/28/EC promoting the use of energy from renewable sources; however, it is in stark contradiction with the power market deregulation efforts ongoing in Latvia since 2013, when it joined the Nord Pool market operating since the mid-1990s.

In the given situation, RES producers are not incentivized to participate in the free electricity market in Latvia, 
because the subsidized tariff substantially exceeds the market price. The achievement of the strategic goal of higher penetration of wind power energy comes at the cost of deviations from the principals of market economy. That is justified only if it results in at least equally valuable positive externality to the society. Moreover, subsidies that are not meant to support technologies at the early stages of their development cycle can be wasteful in the long run. Therefore, it is important to address the problem of high project risks without eliminating the aspect of the free market discipline. Operational uncertainty, on the other hand, can be reduced through modelling efforts, more transparent technical data availability and long-term wind speed measurements at high altitudes.

This paper addresses the question of operational and economic uncertainty of wind projects in Latvia in the absence of state subsidies in the context of a liquid, integrated and free electricity market. The goal of the study is to create a practical basis for decision-making under uncertainty in wind energy projects based on publicly available electricity price data, producer provided technical characteristics of wind generator power curves and experimental wind speed measurements.

The rest of the paper is organized as follows. Section 2 describes the data used in the study and the outcome of wind speed extrapolation exercise. Section 3 covers the results of time series pre-testing procedures. Section 4 outlines methodological approach to times series modeling. Section 5 presents the results of the SDE model calibrations. Section 6 presents the results of out of sample revenue and efficiency forecasts. Section 7 discuss the implications of the main findings and concludes.

\section{Data}

The study is based on the daily average time series of electricity prices for the period of 01/01/2013 - 12/05/2015 from the Latvian segment of Nord Pool power market and a set of high frequency observations of wind speed at the heights of up to $50 \mathrm{~m}$, carried out in the north-western part of Latvia - Irbene, Ventspils region. The wind speed measurements were performed continuously over 698 days during the period of $14 / 06 / 2013$ - 12/05/2015. The summary statistic of the time series is presented in Table I.

Table I. - Summary statistics of the time series of electricity price and wind speed data

\begin{tabular}{|c|c|c|c|c|c|c|c|c|}
\hline Time series & Period & Frequency & Observations & Min & Average & Max & St.dev. & Source \\
\hline $\begin{array}{l}\text { Electricity prices } \\
\text { (EUR/MWh) }\end{array}$ & $\begin{array}{l}01 / 01 / 2013- \\
12 / 05 / 2015\end{array}$ & $\begin{array}{c}\text { Daily } \\
\text { average }\end{array}$ & 862 & 21.3 & 47.3 & 126.3 & 12.2 & Nord Pool \\
\hline $\begin{array}{l}\text { Wind speed at } \\
20 \mathrm{~m}(\mathrm{~m} / \mathrm{s})\end{array}$ & $\begin{array}{l}14 / 06 / 2013- \\
12 / 05 / 2015\end{array}$ & $\begin{array}{l}-10 \mathrm{~min} \\
\text { average }\end{array}$ & 100211 & 0.4 & 2.8 & 12.9 & 1.6 & $\begin{array}{l}\text { Latvia, Ventspils } \\
\text { region, Irbene }\end{array}$ \\
\hline $\begin{array}{l}\text { Wind speed at } \\
30 \mathrm{~m}(\mathrm{~m} / \mathrm{s})\end{array}$ & $\begin{array}{l}14 / 06 / 2013- \\
12 / 05 / 2015\end{array}$ & $\begin{array}{l}10 \mathrm{~min} \\
\text { average }\end{array}$ & 100211 & 0.4 & 3.5 & 15.5 & 1.7 & $\begin{array}{l}\text { Latvia, Ventspils } \\
\text { region, Irbene }\end{array}$ \\
\hline $\begin{array}{l}\text { Wind speed at } \\
40 \mathrm{~m}(\mathrm{~m} / \mathrm{s})\end{array}$ & $\begin{array}{l}14 / 06 / 2013- \\
12 / 05 / 2015\end{array}$ & $\begin{array}{c}10 \mathrm{~min} \\
\text { average }\end{array}$ & 100211 & 0.4 & 4.3 & 16.1 & 1.9 & $\begin{array}{l}\text { Latvia, Ventspils } \\
\text { region, Irbene }\end{array}$ \\
\hline $\begin{array}{l}\text { Wind speed at } \\
50 \mathrm{~m}(\mathrm{~m} / \mathrm{s})\end{array}$ & $\begin{array}{l}14 / 06 / 2013- \\
12 / 05 / 2015 \\
\end{array}$ & $\begin{array}{c}10 \mathrm{~min} \\
\text { average }\end{array}$ & 100211 & 0.4 & 4.6 & 18.7 & 2.0 & $\begin{array}{l}\text { Latvia, Ventspils } \\
\text { region, Irbene }\end{array}$ \\
\hline
\end{tabular}

Fig. 1 shows that daily electivity prices can be highly volatile and exhibit seasonality patterns, that implies that the times series should be de-seasonalized prior to the analysis. Fig. 2 present the results of daily averaging of wind measurements performed using NRG LOGGER Symphonie 9200 mounted on a 50m mast [2].

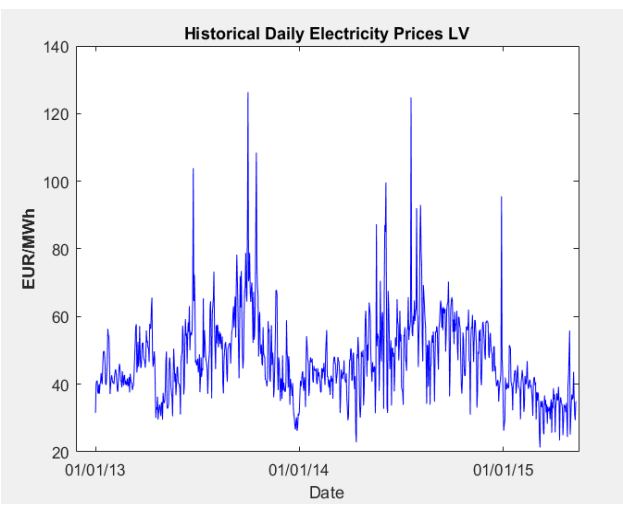

Fig. 1. Electricity prices in the Latvian segment of Nord Pool power market

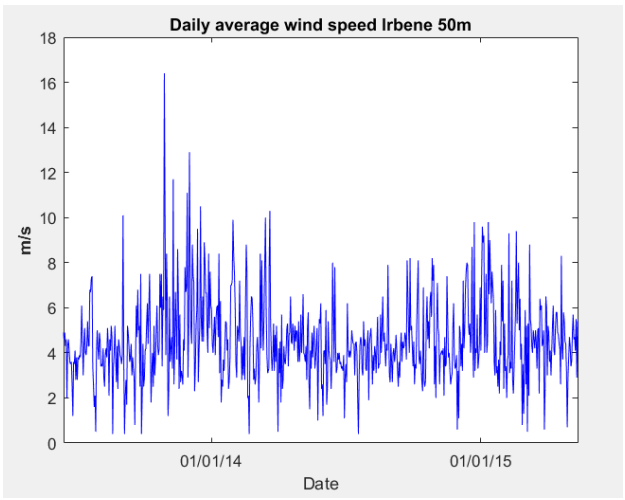

Fig. 2. Wind speed in Irbene, Ventspils region, Latvia at the altitude of $50 \mathrm{~m}$.

In real life wind energy projects, it is common that longterm data on wind measurements is scarce. In the cases when historical measurements data are available, the maximum height of observation towers is limited to 50-60 meters, as the construction of higher masts is usually not practical for small-scale projects. It is also the case for the current study, that is based on wind speed measurements conducted at the altitudes 20,30, 40 and 50 meters. However, in order to assess future revenue potential of a certain geographical location, coupled with wind turbine efficiency estimates, it is necessary to possess data on wind speed at the altitudes of up to $140 \mathrm{~m}$. For that reason, the usual first step in the assessment of wind energy project feasibility consists of estimating wind speed at the altitudes significantly above which physical measurements were made. For the purpose of the current study power law relationship between contemporary wind speed measurements and their height was used in accordance with Eq. 1 (see Fig. 3)

$$
\ln \left(S_{i}\right)=\ln \left(\beta_{0}\right)+\beta_{1} * \ln \left(H_{i}\right)
$$

where:

$\boldsymbol{S}_{\boldsymbol{i}}-$ wind speed $(\mathrm{m} / \mathrm{s})$

$\mathbf{H}_{\mathbf{i}}-$ height (m)

Parameters $\boldsymbol{\beta}_{\mathbf{0}}$ and $\boldsymbol{\beta}_{\mathbf{1}}$ were estimated for the set of actual wind measures every $10 \mathrm{~min}$ and used to contemporaneously extrapolate wind speed values to 80 , 90, 100 and 110 meter altitudes. The results of the extrapolation and daily averaging are summarized in Table II. 


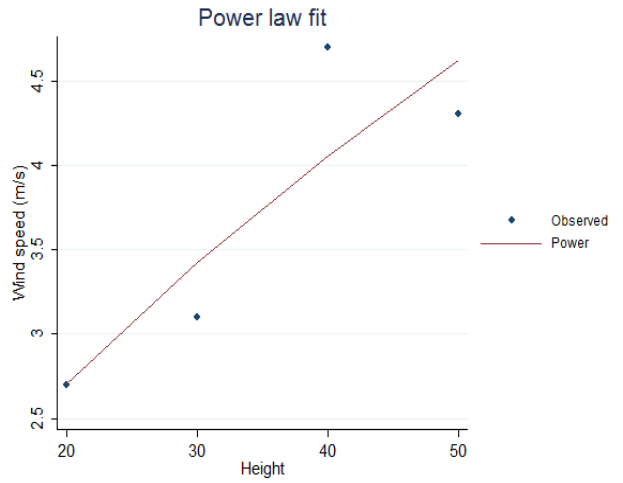

Fig. 3. Power low fit of wind speed in relationship to observation height.

Table II. - Summary statistics of extrapolated wind speed data \begin{tabular}{lccccc} 
Time series & Period & Frequency Observations & Min & Average Max & St.dev. Source \\
\hline Wind speed at & $14 / 06 / 2013-$ & Daily & Powerlaw
\end{tabular}

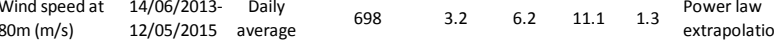
Wind speed at 14/06/2013- Daily $\begin{array}{lllllllll}90 \mathrm{~m}(\mathrm{~m} / \mathrm{s}) & 12 / 05 / 2015 & \text { average } & 698 & 3.6 & 6.7 & 11.6 & 1.4 & \text { extrapolation }\end{array}$ Wind seed at $14 / 06 / 2013$ - Daily $\begin{array}{llllllll}698 & 3.8 & 7.2 & 12.3 & 1.5 & \text { Powerlaw }\end{array}$ (14) $\begin{array}{llllllll}698 & 4.0 & 7.7 & 14.4 & 1.6 & \text { Powerlaw }\end{array}$

\section{Pre-testing procedures}

This section covers the approach towards time series pretesting approach and outlines the implications of the pretesting procedure results for SDE modelling.

Prior to modelling historical time series, it is necessary to determine their general statistical properties. Time series pre-testing procedures involve checking for fat tails of the probability density function (PDF), checking for mean reversion and checking for seasonal patterns. The presence of autoregressives (AR) properties can be tested in the data typically on the returns of a series or on the series itself. In linear processes with normal shocks, this amounts to checking for stationarity [1]. The stationarity of time series can be an indication for mean reversion. If time series are stationary, it can be assumed that the underlying data generating process is mean reverting. Another pre-requisite for making fitting distributional assumptions about the model parameters is the examination of the actual distribution of the time series.

In order to test the data for normality, first we transform the data by taking natural logarithm, and then apply standard tests for normality - Kolmogorov-Smirnov test, as well as Jarque-Bera test. The results of testing log wind speed data suggest that the null hypothesis of normality for extrapolated wind speed data at $100 \mathrm{~m}$ altitude cannot be rejected at 5\% significance level for the log wind speed data, while for $\log$ electricity prices the null hypothesis is rejected at $5 \%$ by Jarque-Bera test. Fig. 4 and Fig. 5 compare the probability density function (PDF) of log wind speed and $\log$ electricity prices to the standard normal PDF.

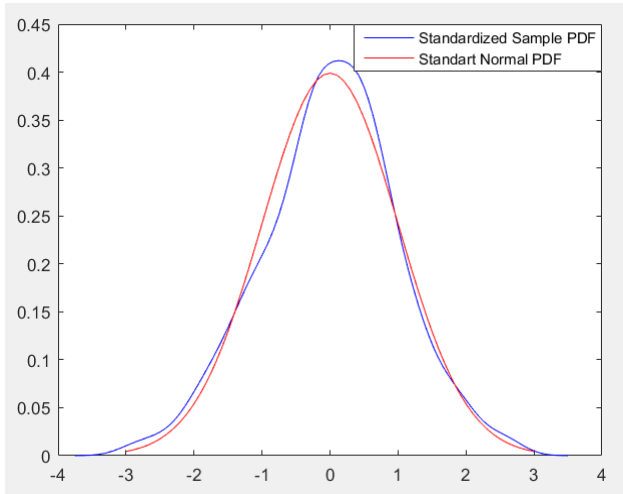

Fig. 4. PDF of log wind speed vs standard normal PDF.

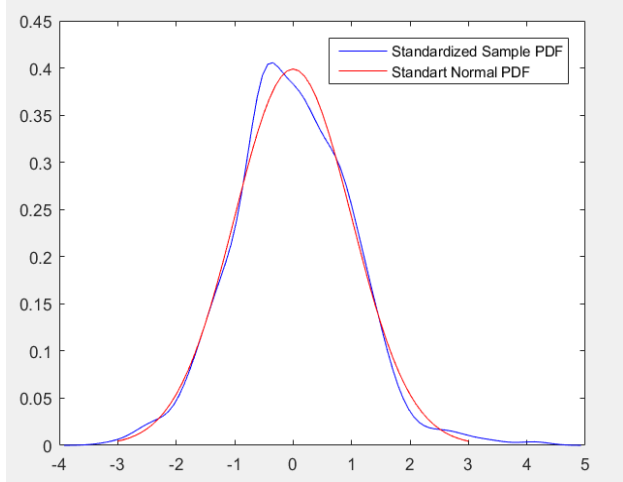

Fig. 5. PDF of log energy prices vs standard normal PDF.

Apart from testing the distributional characteristics of the data it necessary to test whether mean reversion properties are present in the times series. Fig. 6 visualizes the autoregressive properties of $\log$ wind speed, while Fig. 7 serves the same purpose for log energy prices time series. The results of formal tests for stationarity, such as Augmented Dickey-Fuller (ADF) and Kwiatkowski, Phillips, Schmidt, and Shin (KPSS) confirm that the hypothesis of stationarity of the time series cannot be rejected for both time series. The results of the pre-testing procedures for all time series are summarized in Table IV of the Annex.

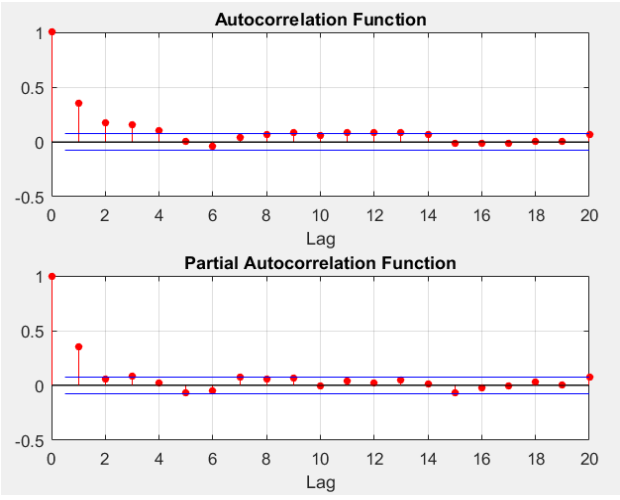

Fig. 6. Autocorrelation Functions of extrapolated log wind speed at $100 \mathrm{~m}$. 


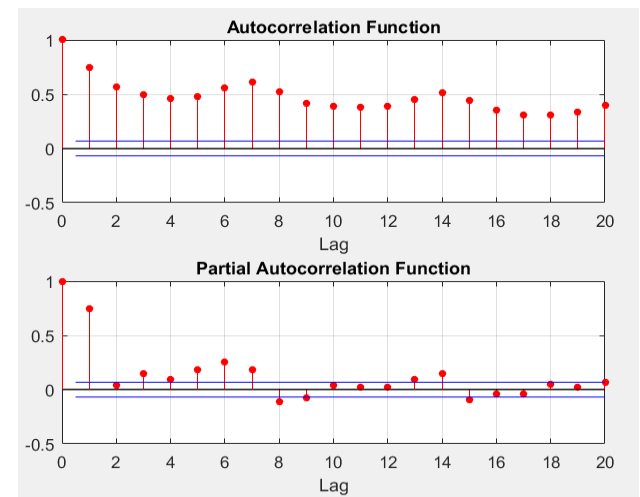

Fig. 7. Autocorrelation Functions of log electricity prices time series.

Overall conclusion from the pre-testing procedures with respect to log wind speed and log energy prices data is that the time series can be modelled as a stochastic mean reverting process with Gaussian diffusion using an Ornstein-Uhlenbeck type process such as Vasicek model [3]. However, given that the electricity price data cannot be assumed to be normally distributed, the model of this time series also has to include jump diffusion elements [4]. On top of this, electricity price time series exhibit seasonal patterns that have to be removed prior to modelling.

\section{Methodology}

As suggested by the pre-testing procedures, log wind speed time series can be modelled by an Ornstein-Uhlenbeck stochastic processes with mean reverting drift and Gaussian diffusions. The process is stationary, Gaussian, and Markovian. Over time, the process tends to drift towards its long-term mean. The Ornstein-Uhlenbeck process can be considered as the continuous-time analogue of the discretetime AR(1) process. It can be calibrated to historical data by performing a linear regression between the state variables and their first difference.

Wind speed data can be modelled using a standard Vasicek model:

$$
\begin{gathered}
\log \left(S_{t}\right)=\mathrm{x}_{t} \\
d \mathrm{x}_{t}=a\left(\theta-x_{t}\right) d t+\sigma d W_{t}
\end{gathered}
$$

where:

$S_{t}-$ wind speed

$a$ - mean reversion speed (the rate of mean reversion $a>0$ )

$\theta$ - mean reversion level (long-run mean or level)

$\sigma$ - instantaneous volatility rate $(\sigma>0)$

$d W t$ - standard Wiener process (standard Brownian motion).

In comparison to the wind speed data, electricity prices have a prominent seasonal component that has to be considered prior to modelling. As suggested by Lucia and Schwartz, the deterministic seasonal trend of the electricity prices is modelled using a combination of trigonometric functions (see Fig. 8 and Eq. 6) [5]. First, the deterministic seasonality part is calibrated using the least squares method. Second, after the calibration, the seasonality is removed from the logarithm of the prices (see Fig. 9).

$$
\begin{gathered}
\log \left(P_{t}\right)=f(t)+\mathrm{x}_{t} \\
d \mathrm{x}_{t}=a\left(\theta-x_{t}\right) d t+\sigma d W_{t}+J\left(\mu_{J}, \sigma_{J}\right) d \Pi(\lambda) \\
f(t)=s_{1} \sin (2 \pi t)+s_{2} \cos (2 \pi t)+s_{3} \sin (4 \pi t)+s_{4} \cos (4 \pi t)+s_{5}
\end{gathered}
$$

where:

$P_{t}-$ spot electricity price

$s_{i}$ - constant parameters

$d \Pi(\lambda)$ - Poisson process with jump intensity $\lambda$

$J_{t}$ - jump size with normally distributed mean $\mu_{J}$ and variance $\sigma_{J}$

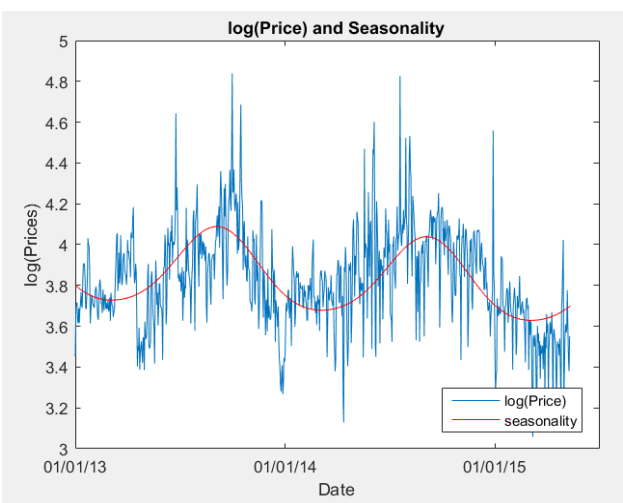

Fig. 8. Log electricity price and seasonality trend.

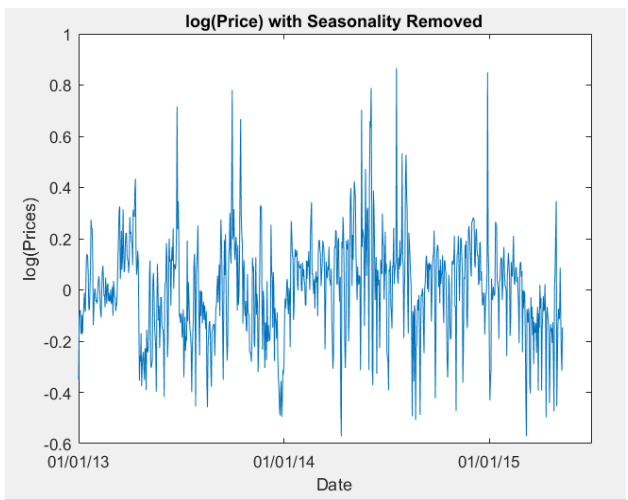

Fig. 9. De-seasonalized log electricity prices.

The model addresses the features of electricity prices time series: fat tails, mean reversion and seasonality. The logarithm of electricity price is modeled with two components:

- deterministic seasonal part $f(t)$ is modeled by trigonometric functions

- $\quad$ stochastic part $x_{t}$ is modelled by mean reverting diffusion process with jumps

Electricity price model adds jumps to a mean reverting process, assuming Poisson jumps (at most one jump per day). Overall, the process in short time instants features extreme movements beyond the Gaussian statistics, and in the long run features mean reversion.

Once the time series modelling process has been chosen and necessary seasonality adjustments are considered, the model parameters have to be calibrated to historical data, typically through OLS regression or maximum likelihood estimation. 


\section{Model calibration}

Vasicek model of log wind speed data can be calibrated to historical data by performing a linear OLS regression between log wind speed and the first difference (see Eq. 7).

$$
\frac{\Delta x_{t}}{\Delta t}=\mathrm{a} \theta-a x_{t}+\frac{\sigma}{\Delta t} d W_{t}
$$

In order to calibrate the SDE model with jump diffusion part, it necessary to discretized it (see Eq. 8 and 9). To discretize, we assume a Bernoulli process for the jump evets with probability $\lambda \Delta t$ :

$$
\Delta x_{t}=a \theta \Delta t-a x_{t-1} \Delta t+\sigma \Delta W_{t}^{A}+\mu_{J}+\sigma_{J} \Delta W_{t}^{B}
$$

and with no jump event probability $(1-\lambda \Delta t)$ :

$$
\Delta x_{t}=a \theta \Delta t-a x_{t-1} \Delta t+\sigma \Delta W_{t}^{A}
$$

where $W_{t}^{A}$ and $W_{t}^{B}$ are independent standard Wiener processes. The calibration of the model is performed using Maximum Likelihood approach [6]. The result of the model calibration is presented in Fig. 10 for wind speed and in Fig. 11 for electricity prices. The resulting model parameter values are summarized in Table $\mathrm{V}$.

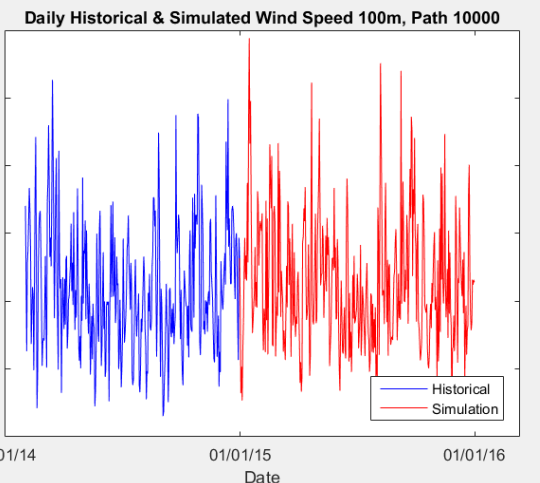

Fig. 10. Actual and Simulated wind speed at $100 \mathrm{~m}$ altitude.

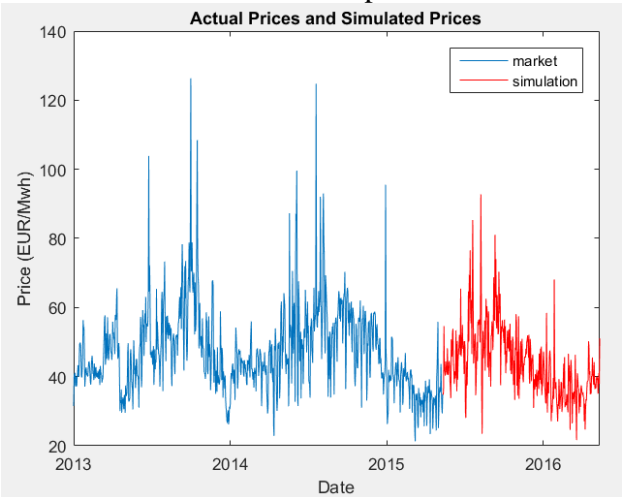

Fig. 11. Actual and Simulated electricity prices.

\section{Results}

Wind project development decision-making process has to answer several questions that are going to define the next ten to twenty years of its operations, locking in the success or failure of the project. Apart from the choice of the initial

${ }^{1}$ Full capacity equivalent - the amount of energy produced during non-interrupted operations at $100 \%$ of the nominal power. geographical location, the strategic decisions include the model of wind generators to be used on the pre-selected location and the height of support towers. In order to address these two questions, it is necessary to assess the revenue potential and future efficiency of the considered wind generator power plant. The quantitative assessment should take into consideration a range of technical and economic factors. In contrast to the historical data on wind speed and electricity prices that can be objectively measured, the choice of a wind power generator model can be subjective.

The current study helps to address the uncertainly arising from volatile weather and market conditions, incorporating modelling of stochastic processes into technical limitations of operational efficiency associated with wind generator power curves. In that respect, we have chosen to consider three different generator models Nordex N54/1000, Siemens SWT-2.3-101 and Nordex $\mathrm{N} 131 / 3000$ in order to compare their hypothetical performance at the chosen location. The first two generator models are actively used in the Latvian conditions with more than ten units installed in the northwestern part of the country, while the third generator is not yet represented in Latvia. The join-up of the manufacturer's power curve specification of Nordex N131/3000 with one year-ahead wind speed forecast at different altitudes is present in the form of the distribution of operational efficiency measure in Fig. 12. The wind speed forecast implies that the wind turbine, if installed on a $100 \mathrm{~m}$ tower, would be operating approximately $44.3 \%$ of the time of the full capacity equivalent ${ }^{1}$.

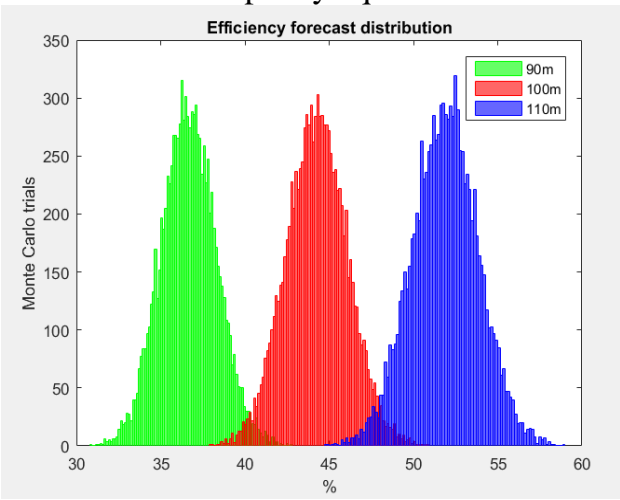

Fig. 12. Histogram of operational efficiency based on 10000 Monte Carlo trials for Nordex $1313000 \mathrm{~kW}$ for different tower heights .

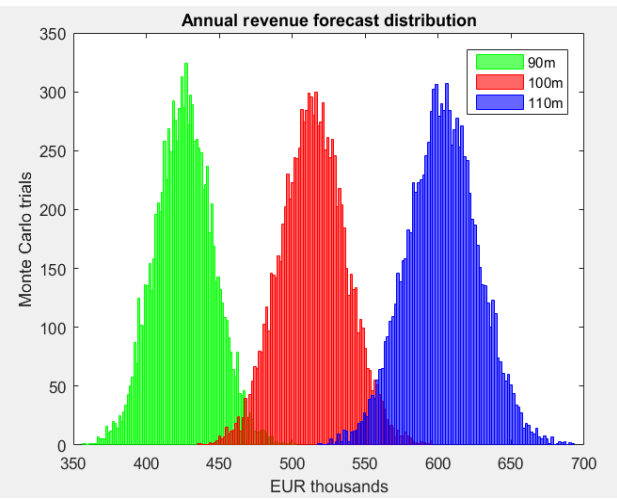

Fig. 13. Histogram of revenues based on 10000 Monte Carlo trials for Nordex $1313000 \mathrm{~kW}$ for different tower heights. 
Fig. 13 brings together the results of the one year ahead electricity price and operational efficiency forecast in order to provide an estimate of revenues obtained from selling generated electricity at the projected market prices. The results of the modelling exercise and Monte Carlo simulation show that the operational efficiency is highly dependent on the type of generators chosen for the project and very sensitive to the height at which the generator is going to operate. Summary results for all three generator types are presented in Table VI in the Annex.

\section{Conclusions}

The paper used historical daily data on electricity prices in the Latvian segment of the Nord Pool power market for the period of 2013-2015 in combination with long term wind speed measurements performed in Irbene, Latvia at the altitude of up to $50 \mathrm{~m}$. Extrapolation approach based on power law functional relationship between the wind speed and altitude was used to obtain the estimates of wind speed at higher altitudes.

In the course of the study, several SDE models were calibrated to historical data and used to forecast operational efficiency of three wind generator types, along with the resulting revenue distribution. The revenue forecast takes into consideration seasonal patterns and stochastic jumps in electricity prices. Overall, the results of the study show that forecasted efficiency and revenue potential are highly dependent on the initial choices of the generator model and can range from $12 \%$ for old, but still operational in Latvia, wind generators Nordex N54/1000 to 52\% for new Nordex N131/3000 model. The study showed that 2.3MW Siemens generators SWT-2.3-101 installed at the largest Latvian wind farm, accounting for one third of wind energy capacity installed in Latvia, might not be optimal for the Latvian conditions. The study suggests that a rigid and multifaceted sensitivity analysis based on physical wind measures and historical electricity market data should be conducted prior to project implementation.

\section{Reference}

[1] Brigo, D., Dalessandro, A., Neugebauer, M. and Triki, F. (2009). A stochastic processes toolkit for risk management: Geometric Brownian motion, jumps, GARCH and variance gamma models. Journal of Risk Management in Financial Institutions, 2: 365-393

[2] Bezrukovs V., A. Zacepins, Vl. Bezrukovs, V. Komasilovs Comparison of methods for evaluation of wind turbine power production by the results of wind shear measurements on the Baltic coast of Latvia. Renewable Energy, RENE-D-15-00512R2, 2015, in print, $18 \mathrm{p}$.

[3] Vasicek, O. (1977). An Equilibrium Characterization of the Term Structure. Journal of Financial Economics, 5, 177-188.

[4] Seifert, Jan, Uhrig-Homburg, Marliese, Modelling Jumps in Electricity Prices: Theory and Empirical Evidence, Review of Derivatives Research, Vol. 10, pp 59-85, 2007.

[5] Lucia, Julio J., Schwartz, Eduaro, Electricity Prices and Power Derivatives: Evidence from the Nordic Power Exchange, Review of Derivatives Research, Vol. 5, Issue 1, pp 5-50, 2002.

[6] Escribano, Alvaro, Pena, Juan Ignacio, Villaplana, Pablo, Modeling Electricity Prices: International Evidence, Universidad Carloes III de Madrid, Working Paper 02-27, 2002.

[7] Review of RES perspective in Baltic countries till 2030 (2015) http://elering.ee/public/Infokeskus/Uuringud/Review of RES pers pective in Baltic countries till 2030.pdf
[8] Kwiatkowski, D., P.C.B. Phillips, P. Schmidt, Y. Shin (1992): Testing the Null Hypothesis of Stationarity against the Alternative of a Unit Root, Journal of Econometrics, 54, pp. 159-178, NorthHolland.

\section{Annex}

Table III. - Installed RES generating capacities in the Baltics, as of 31st December, 2014.

\begin{tabular}{|c|c|c|c|c|c|c|c|}
\hline \multirow{3}{*}{ Source } & \multicolumn{2}{|c|}{ Lithuania } & \multicolumn{2}{|r|}{ Latvia } & \multicolumn{2}{|c|}{ Estonia } & \multirow[t]{2}{*}{ Total } \\
\hline & Total & $\begin{array}{c}\text { Connected } \\
\text { to } \\
\text { transmission } \\
\text { network }\end{array}$ & Total & $\begin{array}{l}\text { Connected to } \\
\text { transmission } \\
\text { network }\end{array}$ & Total & $\begin{array}{c}\text { Connected } \\
\text { to } \\
\text { transmission } \\
\text { network }\end{array}$ & \\
\hline & \multicolumn{7}{|c|}{ …다. } \\
\hline Biofuel & 97 & - & 118 & 24 & 131 & 97 & 346 \\
\hline Hydro & 128 & 101 & 1593 & 1562 & 8 & - & 1729 \\
\hline Solar & 72 & $\cdot$ & 0.68 & $\cdot$ & 3 & $\cdot$ & 76 \\
\hline Wind & 287 & 222 & 67 & 21 & 303 & 274 & 657 \\
\hline TOTAL, MW & 584 & 323 & 1779 & 1607 & 445 & 371 & 2808 \\
\hline
\end{tabular}

Source: Review of RES perspective in Baltic countries till 2030 [7]

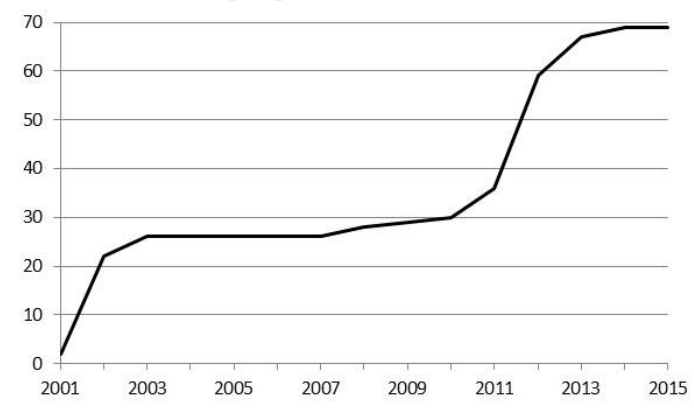

Fig. 14. Installed wind power plant capacity in Latvia in MW SOURCE: Central Statistical Bureaue of Lativa, 2016.

Table IV. - The results of pre-testing procedure for log wind speed and log energy prices.

\begin{tabular}{|c|c|c|c|c|c|}
\hline Test for noramlity (p-values) & $\begin{array}{l}\text { Log Wind } \\
\text { speed at } 80 \mathrm{~m}\end{array}$ & $\begin{array}{l}\text { Log Wind } \\
\text { speed at 90m }\end{array}$ & $\begin{array}{l}\text { Log Wind } \\
\text { speed at } 100 \mathrm{~m}\end{array}$ & $\begin{array}{l}\text { Log Wind } \\
\text { speed at } 110 \mathrm{~m}\end{array}$ & $\begin{array}{l}\text { Log electricity } \\
\text { prices }\end{array}$ \\
\hline Kolmogorov-Smirnov test & 0.24 & 0.16 & 0.23 & 0.31 & 0.50 \\
\hline Jarque-Bera test & 0.36 & 0.32 & 0.30 & 0.42 & 0.00 \\
\hline \multicolumn{6}{|l|}{ Test for stationarity (p-values) } \\
\hline Augmented Dickey-Fuller (ADF)* & 0.00 & 0.00 & 0.00 & 0.00 & 0.13 \\
\hline Kwiatkowski, Phillips, Schmidt, and Shin (KPSS)** & 0.10 & 0.10 & 0.10 & 0.10 & 0.10 \\
\hline
\end{tabular}

\begin{tabular}{llllll} 
Test for random walk (p-values) & & & & & \\
\hline Variance ratio test & 0.00 & 0.00 & 0.00 & 0.00 & 0.00 \\
\hline
\end{tabular}

NOTE: * AUTOREGRESSIVE MODEL WITH DRIFT VARIANT; ** OPTIMAL NUMBER OF LAGS ACCORDING TO KWIATKOWSKI [8].

Table V. - Model parameter calibration results. All quantities are annualized.

Electricity Wind speed at Wind speed at Wind speed at Wind speed at Parameter price model $80 \mathrm{~m}$ model $90 \mathrm{~m}$ model $100 \mathrm{~m}$ model $110 \mathrm{~m}$ model

\begin{tabular}{rrrrrr}
\hline$a$ & 247.35 & 235.05 & 237.39 & 236.22 & 232.59 \\
$\theta$ & 0.01 & 1.81 & 1.88 & 1.95 & 2.01 \\
$\sigma$ & 1.71 & 3.70 & 3.65 & 3.66 & 3.72 \\
$\sigma_{J}$ & 0.21 & - & - & - & - \\
$\mu_{J}$ & -0.02 & - & - & - & - \\
$\lambda$ & 135.62 & - & - & - & - \\
$\Delta t$ & $1 / 365$ & $1 / 365$ & $1 / 365$ & $1 / 365$ & $1 / 365$ \\
\hline
\end{tabular}

Table VI. - Out of sample forecasting results for three types of wind generators. All quantities are annualized.

\begin{tabular}{lcrr} 
Nordex N131/3000 & $\mathbf{9 0 m}$ & $\mathbf{1 0 0 m}$ & $\mathbf{1 1 0 m}$ \\
\hline Revenue mean & 432010 & 514580 & 603020 \\
Revenue st.dev. & 21071 & 22547 & 24536 \\
Efficiency & $37.2 \%$ & $44.3 \%$ & $51.9 \%$ \\
\hline & & & \\
Siemens SWT-2.3-101 & $\mathbf{9 0 m}$ & $\mathbf{1 0 0 m}$ & $\mathbf{1 1 0 m}$ \\
\hline Revenue mean & 264680 & 324610 & 387210 \\
Revenue st.dev. & 13535 & 15504 & 17456 \\
Efficiency & $29.7 \%$ & $36.4 \%$ & $43.5 \%$ \\
\hline & & & \\
Nordex N54/1000 & $\mathbf{8 0}$ & $\mathbf{9 0 m}$ & $\mathbf{1 0 0 m}$ \\
\hline Revenue mean & 47445 & 62050 & 78868 \\
Revenue st.dev. & 3085 & 3727 & 4486 \\
Efficiency & $12.2 \%$ & $16.0 \%$ & $20.4 \%$ \\
\hline
\end{tabular}

